\title{
Otolaryngological Manifestations of Systemic Diseases
}

\author{
Chiraz Halwani ${ }^{1,2 *}$, Safa Trabelsi $^{3}$, Cyrine Zgolli ${ }^{1,2}$, Khémaies Akkari $^{1,2}$, Rania Ben Mhamed $^{1,2}$ and Salem Bouomrani ${ }^{3,4}$ \\ ${ }^{1}$ Department of ENT, Military Hospital of Tunis, Tunisia \\ ${ }^{2}$ Tunis Faculty of Medicine, Tunis El Manar University, Tunisia \\ ${ }^{3}$ Department of Internal medicine, Military Hospital of Gabes, Tunisia \\ ${ }^{4}$ Sfax Faculty of Medicine, University of Sfax, Tunisia
}

Received: 㘹 October 22, 2018; Published: 㘹 October 26, 2018

*Corresponding author: Chiraz Halwani, Department of ENT. Military Hospital of Tunis. Mont Fleury Tunisia, North Africa

\begin{abstract}
Ear-Nose-Throat (ENT) manifestations are among the most frequent clinical features of systemic and rheumatologic disorders. A great variety of pathologies have been described including relapsing polychondritis, granulomatosis, sarcoïdosis and connectivities. Sometimes, ENT manifestations are less common but may be the presenting features and represent a diagnostic challenge. A close collaboration between ENT specialists, rheumatologists, and internists is mandatory to improve the diagnostic and therapeutic management of these patients.
\end{abstract}

Keywords: ENT; Systemic Disorders; Connectivities; Vascularitis; Granulomatosis; Sarcoidosis

\section{Introduction}

Systemic diseases are a broad nosologically framework grouping mainly connectivities, primary vasculitis, systemic granulomatosis and more rarely some related diseases (systemic amyloidosis, primaryantiphospholipid syndrome, auto-inflammatory syndromes or hereditary recurrent fevers). Multi-organ involvements as well as an immune dysfunction are the common signature of these affections [1]. As a result, these diseases are characterized by an important clinical polymorphism making their diagnosis a real challenge for the clinician. Otorhinolaryngological (ENT) lesions are among the most frequent manifestations observed during these diseases [2-7] but are most often neglected or trivialized [8,9]. On the other hand, they can in some cases inaugurate the diagnosis and even condition the prognosis $[3,8,10,11]$. Indeed, in the Iguelouane $\mathrm{N}$ et al series, ENT involvement was noted in $67.5 \%$ of the 200 patients followed in an Internal Medicine department for systemic diseases; this involvement was indicative of systemic disease and/ or announcing her relapse in $37.5 \%$ of cases, and in seven of these patients, ENT involvement had resolved the diagnostic problem of systemic disease [12]. The discovery of ENT manifestations during systemic disorders raises the question of their etiology: specific damage of the underlying systemic disease? Simple coincidence?

Or a complication of the satellite immunodepression of these diseases and/or the specific therapies used? This requires their knowledge and close cooperation between ENT specialists, internists and rheumatologists $[4,9,13]$. In daily medical practice, some system diseases, with granulomatosis with polyangiitis (GPA), sarcoidosis, primary Sjogren's syndrome, Bechet's disease, systemic lupus erythematosus (SLE), recurrent polychondritis, eosinophilic granulomatosis with polyangitis (EGPA) and Cogan syndromes are conditions commonly encountered by ENT physicians [4,9]; However, these manifestations are not well known by most of them $[4,9,12]$. In the Gera C and Kumar N Indian study of 29 ENT specialist physicians, $82 \%$ felt that they had not been adequately trained in ENT involvement of systemic diseases and felt it was necessary to additional training on ENT manifestations of systemic diseases [9]. Through this focus, we describe the ENT manifestations of the main system diseases and detail their diagnostic, therapeutic and prognostic features, while using a review of the literature and some illustrations from our personal series.

\section{Systemic Vasculitis}

\section{GPA, Formerly Wegener's Disease}

GPA is a very rare disease, classified as a systemic necrotizing vasculitis and is characterized by granulomatous inflammation of the wall of small vessels and the presence in patients' serum of autoantibodies directed against the cytoplasm of neutrophils (ANCA) with cytoplasmic enhancement in indirect 
immunofluorescence (c-ANCA), and anti-proteinase 3 (PR3) specificity $[14,15]$. It can occur in two forms: localized or systemic, and the presence or absence of renal impairment that differentiates these two presentations [14,15]. ENT manifestations, besides pulmonary and renal manifestations, are the most frequent manifestations of the disease [16,17]. ENT involvement, present in approximately $70 \%$ of patients at some point during vasculitis, is often indicative $[11,18]$; in fact, ENT manifestations inaugurated the disease in $80 \%$ of patients with GPA in the Register F et al series [11]. The symptoms presented are typically persistent nasal obstruction, nasal pain, sinusitis and trailing rhinitis, possibly hemorrhagic and/or crusted. Rarer are repeated epistaxis, serous otitis media, and or hearing loss $[2,4,14]$. Examinations of the nasal fossae range from crusted mucous-purulent rhinitis to cartilaginous destructive lesions (septal perforation) or bone destruction of the nasal pyramid $[2,16,17]$. These destructions can thus lead to a saddle nose deformity which is characteristic of the disease in $20 \%$ of patients $[2,16,17]$. Computed tomography of the facial mass in the parenchymal window and in the bony window may show Uni or bilateral sinusitis (thickening of the sinus mucosa, complete filling of the sinus lumen, air-liquid level), bone destruction and/ or lysis of the cartilages of the nose (mainly the nasal septum) and osteosclerosis (Figure 1) [19].

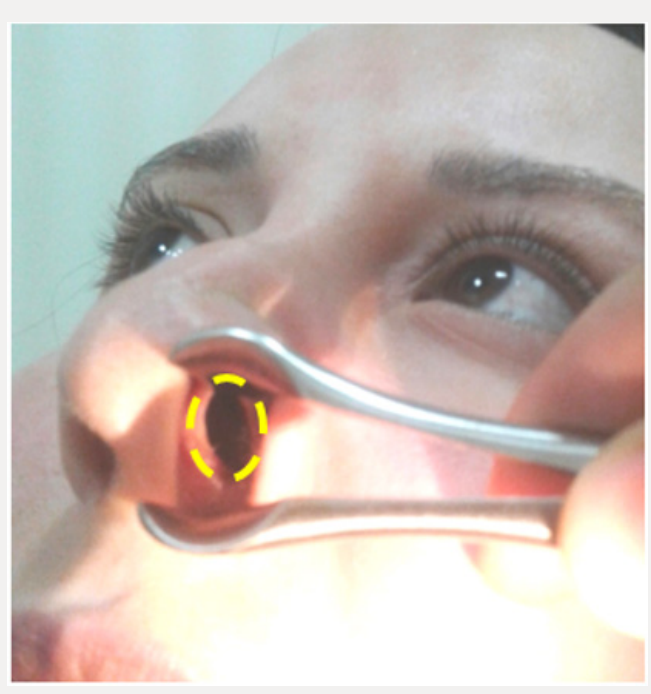

Figure 1: Perforation of the large nasal septum visible by anterior endoscopy.

Biopsies of the nasal and/or sinus lesions can provide, in about half of the cases, histological confirmation, if they are multiple and sufficiently deep, by objectifying the necrotizing vasculitis and the presence of the perivascular non-caseating granuloma [20]. Subglottic stenosis is rare (7 to $10 \%$ of patients) [10], responsible for dysphonia and/or laryngeal dyspnea and often associated with endo-bronchial localization of the disease $[2,16,17]$. More rarely, we can notice involvement of the main salivary glands with a pseudotumoral aspect of the parotid or submaxillary glands (3\% of cases), deafness, involvement of the flag of the ear or a spontaneous perforation of the lobule of the ear or nasal septum $[18,21,22]$. In diffuse forms, treatment is classically based on the combination of systemic corticosteroids and certain immunosuppressants and more recently on targeted biotherapy; While in localized/limited forms, some authors are content with a less aggressive treatment based on sulfamethoxazole-trimethoprim [2,14,16,17].

\section{EGPA, Formerly Churg and Strauss Syndrome}

EGPA is a necrotizing systemic vasculitis of small vessels. The main features of this condition are the existence of severe asthma and significant blood and tissue eosinophilia, associated with visceral extra-pulmonary involvement like that observed during periarteritis nodosa [23]. The ENT involvement of EGPA is primarily rhino logical and is observed in more than $60 \%$ of patients $[2,8,13,24-26]$. Allergic rhinitis is common $(70 \%)$ in the initial phase of the disease $[2,8,27]$ causing nasal obstruction, sinusitis and nasal polyposis $[2,8,13,24-26]$. It is the association with lateonset and severe asthma that most often suggests the diagnosis of GEPA. More rarely are otitis, recurrent epistaxis, maxillary sinusitis and peripheral facial palsy $[2,8,13,24-26]$. Unlike GPA, the EGPA's ENT lesions are neither deforming nor destructive. Beside these manifestations, the clinical examination must look for systemic signs (purpura, mononeuropathy or polyneuritis, digestive or cutaneous signs) [28] whose presence makes it possible in general to carry the diagnosis. The 3 most cost-effective biopsy sites for the histological diagnosis of this vasculitis are skin, nerve and muscle [23]. Biopsies of the nasal mucosa typically find granulomatous material rich in eosinophils. The prognosis of the condition has been transformed by the introduction of corticosteroids and immunosuppressants [2,8,13,24-27].

\section{Cogan's Syndrome}

Cogan's syndrome is a chronic inflammatory disease that evolves through relapses that is characterized by the association of non-syphilitic interstitial keratitis, most often bilateral, with cochleo-vestibular involvement [30]. This cochleo-vestibular involvement is part of the definition of Cogan syndrome as well as ocular involvement [31,32]. Indeed, in the large series of Gluth MB et al, 60 patients with Cogan syndrome recruited over 60 years, this cochleo-vestibular involvement was noted in most patients and was type of hypoacusia or sudden deafness in half of the cases [32]. The vestibulo-cochlear symptoms during Cogan's syndrome are the same as those of Meniere's disease and this semi logical similarity can pose a problem of differential diagnosis. The mode of presentation with brutal installation vertigo, hearing loss and tinnitus constitutes the most frequently encountered symptomatic triad, which reflects the bilaterality of the attack. Examination may show spontaneous nystagmus and some degree of ataxia [33]. This ataxia to walking is more marked than vertigo, a ratio most often reversed in Meniere's disease [19]. It is followed by a hearing deficit which increases rapidly and leads to a bilateral deafness of progressive and generally definitive installation [34]. This complication was noted in $52 \%$ of patients in the Gulth MR et al series [32]. Audio-vestibular manifestations result from damage 
to the inner ear which is often irreversible because it is associated with degeneration of the sensory organ of Corti $[35,36]$.

The pathogenetic mechanism of this involvement and of the disease in general, was recently recognized as a diffuse primary vasculitis that has classified Cogan syndrome as a primary systemic vasculitis since the 2012's review of the Chapel Hill consensus [37]. The MRI of the inner ear may show, especially in the acute phase, an appearance of labyrinthitis, or a T1 hyperintense of gadolinium-enhanced cochleo-vestibular structures [38]. Other systemic manifestations are present in 70\% of Cogan's syndromes: polyarthralgia, synovitis, central neurological manifestations, and digestive or cutaneous involvement; they signify the systemic nature of this affection and guide the diagnosis [39]. Treatment of Cogan syndrome involves systemic corticosteroids associated with local corticosteroids and mydriatics [32]. The vestibular syndrome regresses in few days to few months and leads to severe deafness in $80 \%$ of cases, first unilateral then bilateral, despite treatment with corticosteroids and/or immunosuppressants [32,40]. Cochlear implants, in case of permanent deafness, have transformed the prognosis of the disease [32].

\section{Susac's Syndrome}

It is a rare condition caused by vasculopathy of unknown etiology that affects the small vessels of the brain, retina and cochlea [41]. The main features of this syndrome are: subacute encephalopathy often preceded by atypical ophthalmic migraine; biological meningitis, evocative brain imaging, bilateral involvement of the branches of the central artery of the retina with occlusions and cochleo-vestibular involvement $[42,43]$.

\section{Oreille droite}

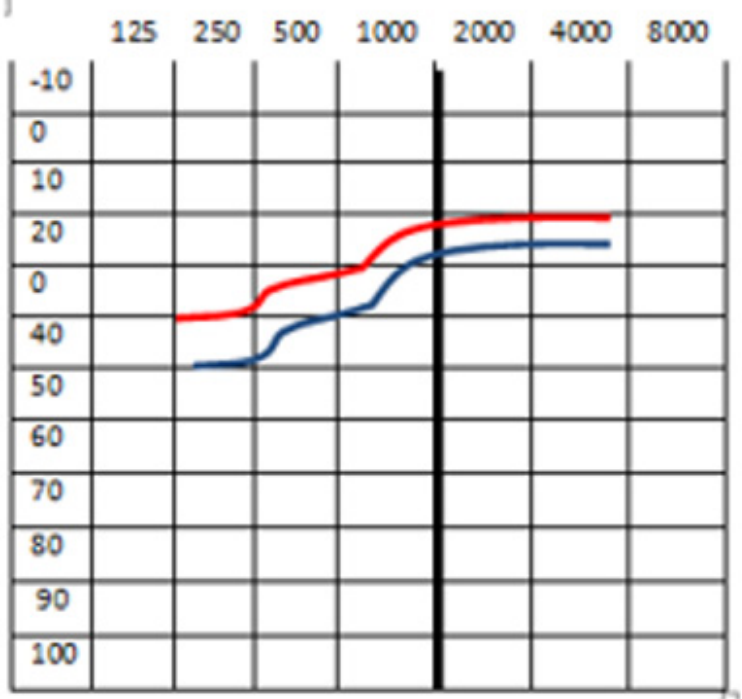

\section{Oreille gauche}

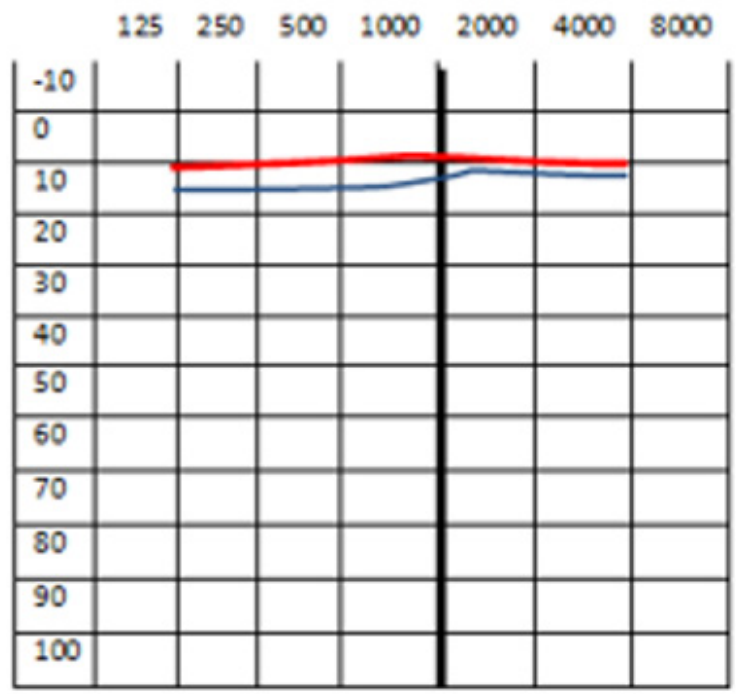

Figure 2: Perceptive deafness predominant on low frequencies (audiogram).

The cochleo-vestibular symptomatology is often acute, bilateral, asymmetrical, with poor verbal discrimination. A sudden hypoacusis with a large rotary vertigo, ataxia and nystagmus can also achieve a mode of entry into the disease [44]. The audiogram found a predominantly characteristic perceptive deafness on low frequencies, and more rarely medium, which would be consistent with ischemic involvement of the apical part of the cochlea (Figure 2). Vestibular hypo reflexivity is observed after caloric stimulation. The differential diagnosis is with multiple sclerosis, acute disseminated encephalomyelitis, systemic vasculitis and Bechet's disease. The evolution is marked by recurrent thrusts that can affect one or more of the three organs. Subsequently, the evolution is dissociated: a remission is obtained in the cephalic sphere and ENT. At this level, the sequelae are often moderate, allowing the return to a normal life in most of the cases. Sometimes a hearing aid or placement of cochlear implants is needed [44]. Cophosis or severe dementia are exceptional [45].

\section{Connectivities and Related Conditions}

\section{Chronic Atrophic Polychondritis}

Chronic atrophic polychondritis (CAP) is characterized by chronic inflammation of cartilage structures, the repetition of which may lead to fibrosis, cartilage destruction and deformity $[10,46]$. ENT sites (the ears, the nose, the laryngo-tracheobronchial sector) are frequent, and often revealing the disease $[4,7,10,47]$. More than $80 \%$ of patients develop chondritis of the ear during the disease. In the acute phase, the auricular flag appears red, hot and swollen and is very painful. Typically, the lobule is spared [4749]. Repeated inflammatory attacks result in the destruction of the cartilage: the pinna becomes soft and folds down, giving the ear a cauliflower appearance. Transmission deafness can occur if there is obstruction of the external auditory canal by edema $[28,49]$. A perception deafness of cochlear origin or in relation to a cerebral vasculitis, frequently associated with a vestibular syndrome, is 
also possible [48]. The association with a nasal chondritis is very frequent but sometimes unknown because the appearance is less inflammatory than the level of the pinna of the ear. The collapse of the nasal septum, which can evolve insidiously, gives the nose an appearance in "saddle" [4].

The involvement of laryngeal and tracheobronchial cartilages is less frequent but serious [50,51]. The latter must be suspected in the presence of usually expiratory dyspnea related to airway collapse. It exposes to repeated pulmonary infections and may be complicated by tracheal or bronchial stenosis. As a result, the laryngeal and laryngo-tracheal lesions, like those of the cardiovascular system, determine the prognosis of this disease [10]. It is important to know how to recognize CAP because a delay in the diagnosis can lead to severe complications. Diagnosis is mainly clinical and ENT manifestations can usually be enough to make the certain diagnosis [10]. In addition, it may be supported by cartilage biopsies and response to treatment [49]. The search for anti-cartilage autoantibodies (directed specifically against type II collagen), if possible to be performed, could be very useful for diagnosis [10]. The assessment should be supplemented by thoracic CT and cardiac echocardiography to rule out airway stenosis or instability and possible aortitis.

Treatment is primarily based on systemic corticosteroids alone or in combination with immunosuppressants [4,47-49]. The prognosis is usually related to laryngotracheal and cardiovascular involvement. The association with myelodysplasia is known $[4,10]$.

\section{Systemic Lupus Erythematosus}

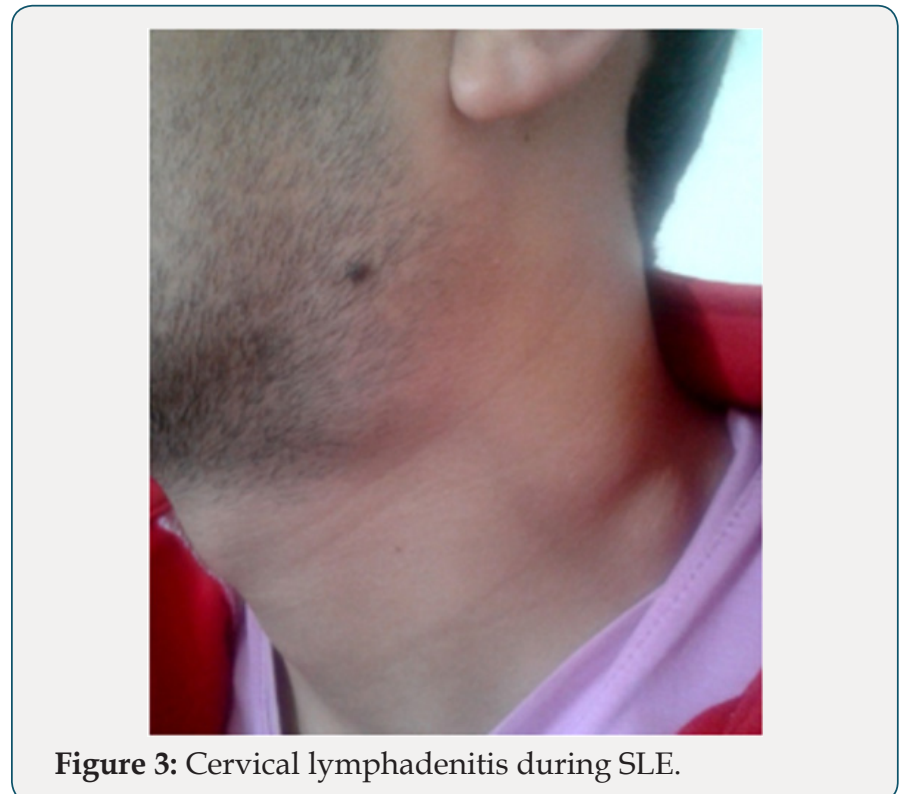

SLE is an autoimmune disease characterized by cutaneous, articular, visceral (kidney, nervous system, serous) and hematologic disorders as well as the presence of autoantibodies directed against nuclear antigens and more specifically the native DNA doublestranded [51]. Among ENT manifestations, cervical polyadenopathy may be inaugural and is frequently found (Figure 3); it can be simple reactive (lupus lymphadenitis) or reveal an associated Kikuchi-Fujomoto syndrome [52,53]. Cases of perforation of the nasal septum caused by lupus have also been noted [22]. Rahman et al, estimated the prevalence of this complication at 4.6\% [54]; these perforations occur classically as a part of a severe and progressive LES.

Oropharyngeal or nasal involvement (ulcerations) is noted in $90 \%$ of patients and is included in the diagnostic criteria [7]; more rarely other manifestations may be noted such as trigeminal neuralgia, facial nerve involvement, vocal cord palsy or specific laryngeal involvement and hearing abnormalities $[4,7,47,55,56]$.

\section{Primary Sjogren's Syndrome}

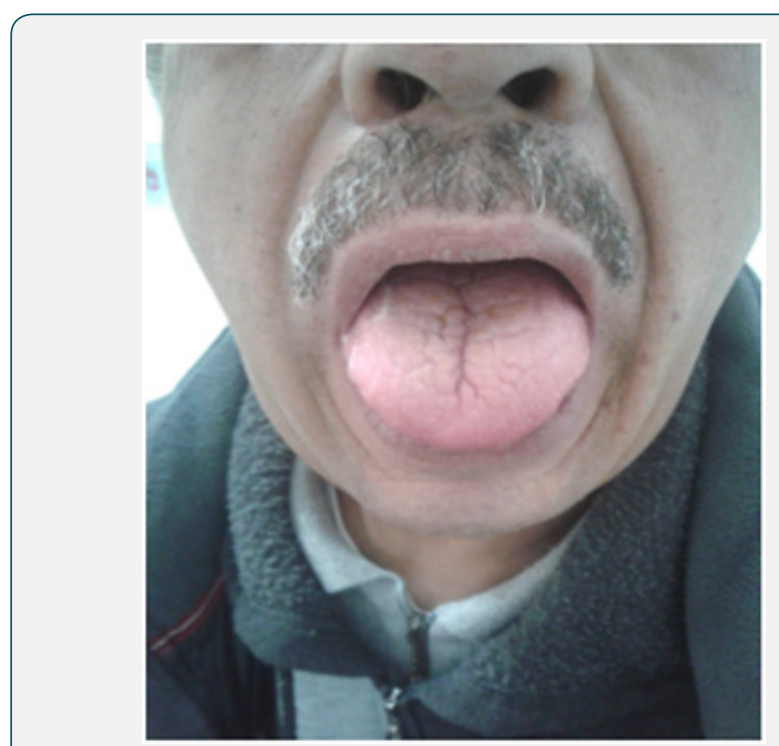

Figure 4: Dry mouth during primary Sjogren's syndrome.

The disease is due to a lymphocytic infiltration of the exocrine glands, mainly salivary and lacrimal, causing a drying up of their secretions [57]. The result is a characteristic oto-rhino-ocular dryness often in the foreground, hence the name of the disease as a "primary sicca syndrome" (Figure 4). The most common ENT involvement is Uni or bilateral parotid swelling, often painless but sometimes painful. Parotid swelling can take several forms: most often episodic progressive installation regressing in 2 to 6 weeks but often recurrent. The attack is often bilateral and symmetrical realizing the Mikulicz syndrome. The swelling may be sensitive and prompts to seek a superinfection at its level. When the swelling becomes fixed without episodic regression, we must fear the lymphomatous transformation, a fearsome complication of the disease [57-59]. This chronic parotitis is almost always associated with xerostomia [59]. More rarely, the disease may manifest as swelling of the sub-mandibular glands, perceptive deafness on acute frequencies, laryngeal granulomas, or Hashimoto's thyroiditis $[57,58]$. The exact pathogenic mechanism of hearing loss/deafness in primary Sjogren syndrome is not well known; it appears to be Dys-immune, involving both the deposition of disease-specific 
autoantibodies on the antigens of the inner ear structures and the infiltration of these structures by self-reactive T lymphocytes [57].

\section{Sarcoidosis}

It is a multi-visceral granulomatous disease, of unknown cause, characterized by tissue infiltration consisting of giant cell tuberculoid granulomas, without associated caseous necrosis $[59,60]$. ENT involvement is noted in 10 to $15 \%$ of patients [61] and raises the problem of differential diagnosis with tuberculosis, GPA and lymphoma [62]. It is mainly represented by cervical lymphadenopathy, Pharyngolaryngeal (1\%) and naso-sinus involvement $(2 \%)[4,47,61]$. The Pharyngolaryngeal involvement is represented by pale pink edema, mainly supraglottic, causing dysphagia, dysphonia and even dyspnea.

The naso-sinus localization is rare, in the form of chronic inflammatory rhinosinusitis, sometimes crusted, resistant to medical treatment, causing chronic nasal obstruction, rhinorrhea, epistaxis, and anosmia (Figure 5) [4,47,61,62]. Neuro-sarcoidosis, responsible for a poly-neuropathy, may cause facial palsy, sometimes bilateral and regressive VII nerve involvement (Figures 6- 8). The IX and X nerves are more rarely affected, as is the VIII (medium-tosevere perception deafness, abrupt or fluctuating, accompanied by vertigo) and for some authors, the ENT involvement must always search for an associated neuro-sarcoidosis [63]. The other possible ENT sites are the nasopharynx, which causes otitis media, and the thyroid (goiter) $[4,47,61]$. At the auricular level, sarcoidosis mainly affects the outer ear (helix and/or ear lobe), middle ear damage is exceptional [64]. Inflammatory sarcoidosis of the club/lobule can mimic CAP [65]. There is also bilateral hypertrophy of the parotid or sub-mandibular glands [66] as well as perforations of the nasal septum [22]. ENT biopsies directed at macroscopic lesions are usually cost-effective and enough for diagnosis [63].

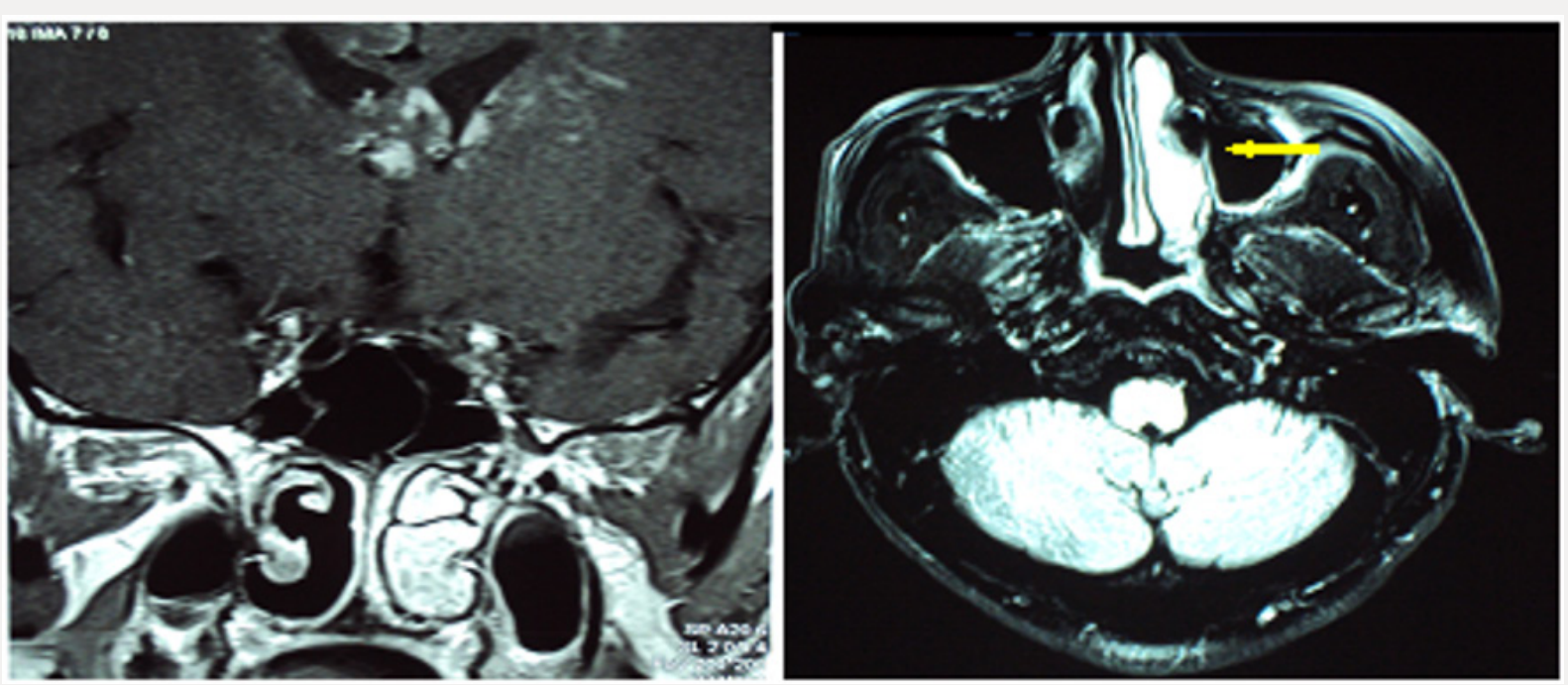

Figure 5: MRI of the facial mass shows significant enhancement of the right inferior turbinate of inflammatory origin during sarcoidosis.

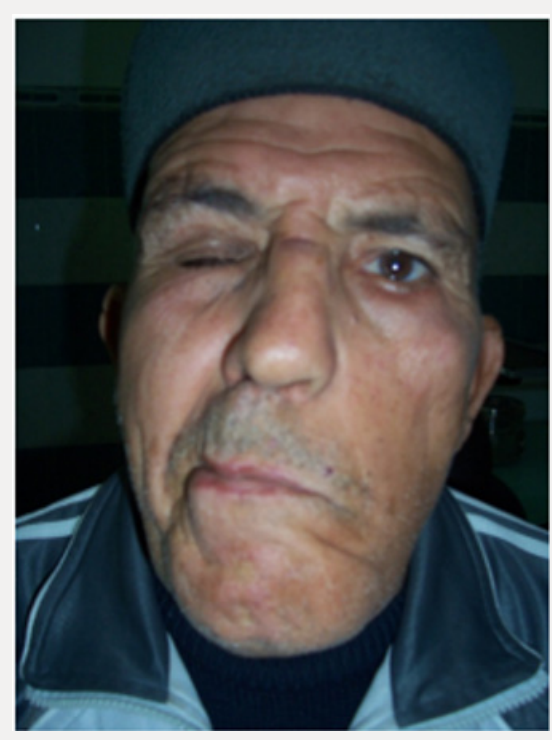

Figure 6: Left peripheral facial nerve palsy related to neurosarcoidosis. 


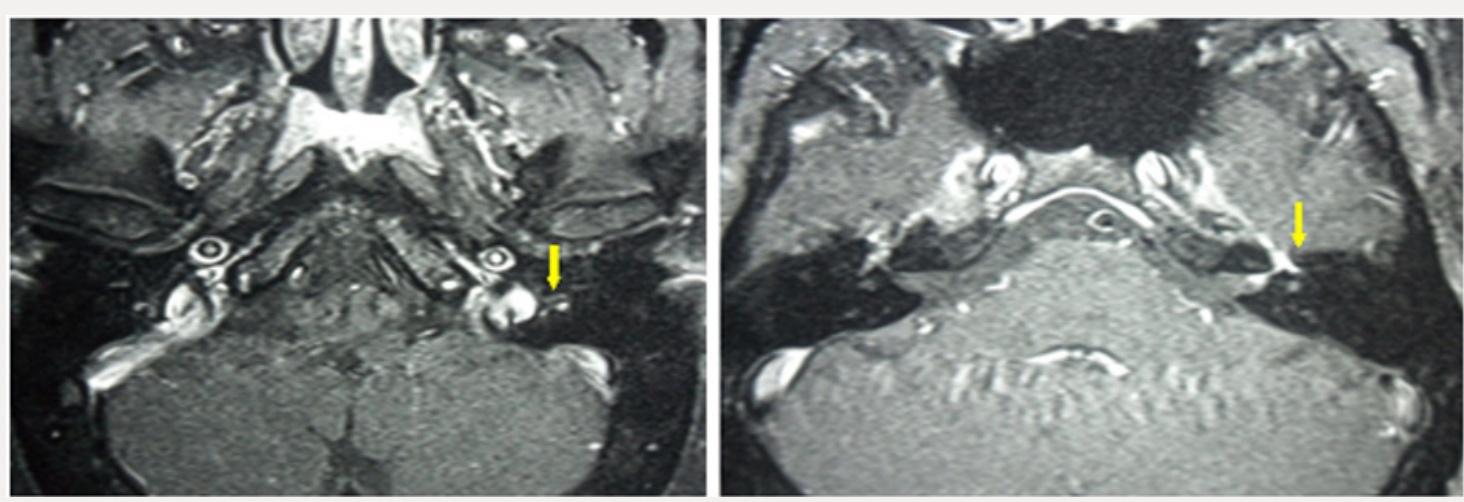

Figure 7: MRI of cerebellopontine angle neuropathy of the left VII nerve.
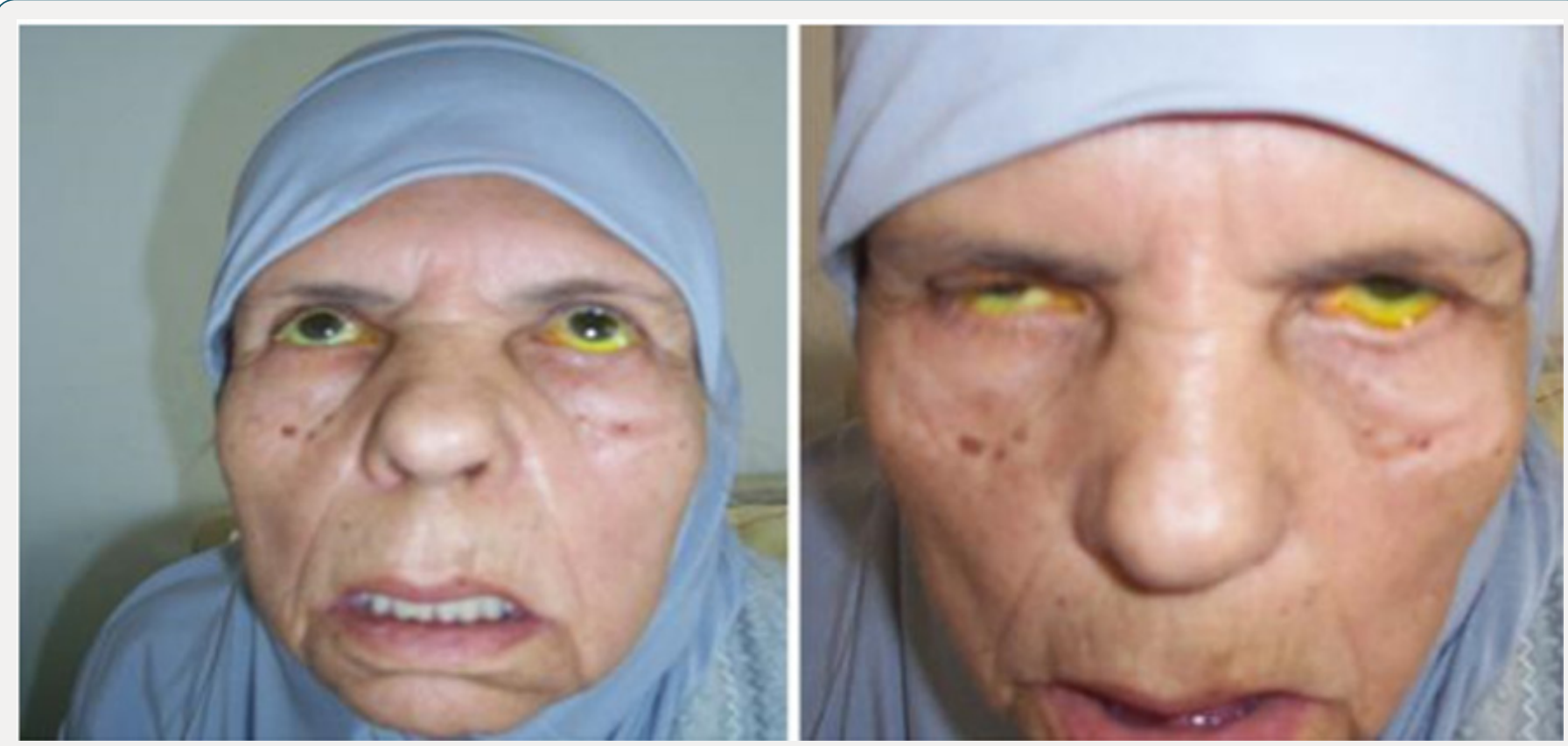

Figure 8: Peripheral facial diplegia.

\section{Other Systemic Diseases}

Many other vasculitis can also be accompanied by ENT involvement. A brutal cochleo-vestibular syndrome may exceptionally inaugurate the clinical picture of giant cell temporal arteritis (Horton's disease) [67]. Exceptional cases of sudden deafness have also been reported in Takayasu's disease [68]. Perceptive deafness is also rarely associated with polyarteritis nodosa. Sero-mucous otitis, sinus or oral lesions may sometimes precede the other symptoms of this disease [62]. Paralysis of the vocal cords can be seen during microscopic polyangiitis $[69,70]$. ENT involvement in Bechet's disease seems far from rare but is often neglected [71]. It remains dominated by oral aphtosis; however, late audio-vestibular involvement is reported in some cases [70,71]. When routinely screened, this audio-vestibular involvement can be found in $15 \%$ of patients with Bechet's disease [72]; it most often comes within the framework of a more serious neurological impairment defining neuro-Bechet and isolated vestibular neuritis may sometimes be the first sign of this vasculitis [72].
Oropharyngeal mucosal involvement and cervical polyadenopathy are among the diagnostic criteria for Kawasaki disease [55], and perforations of the nasal septum can be seen in cryoglobulinemia and the primary antiphospholipid syndrome [22].

\section{Autoimmune Deafness}

In 1979, McCabe identified the entity of autoimmune deafness (AID) [73]. He described them as: "progressive bilateral perceptive deafness, with rapid progressive but not brutal installation, responding favorably to a treatment combining corticosteroids and cyclophosphamide" [73]. Thus, a perception deafness in a young adult may be of an autoimmune nature and we must know how to evoke it when the classic etiological assessment of a sensorineural deafness proves to be negative. There are many systemic diseases that can be associated with autoimmune deafness. The most common are rheumatoid arthritis (35-60\%), CAP (40\%), primary Sjogren's syndrome (46\%), but also systemic sclerosis, SLE, primary antiphospholipid syndrome, Horton's disease, Takayasu's disease, GPA, EGPA, polyarteritis nodosa, Bechet's disease and 
cryoglobulinaemia [74]. The diagnosis remains difficult to make since there is no clinical specificity. There is also no specific diagnostic test for the moment. Corticosteroid treatment should be considered quickly, and the efficacy should be evaluated after one month. In the absence of an answer, the attitude is not yet well codified [74].

\section{Conclusion}

Systemic diseases are a group of various pathologies whose ENT manifestations are relatively common. These manifestations are sometimes revealing or may appear during evolution of the disease. Lack of specificity can misunderstand and delay the diagnosis. Close collaboration between ENT specialists, internists and rheumatologists is essential for the diagnostic and therapeutic approach of these patients.

\section{References}

1. Kane BS, Ndongo S, Ndiaye AA, Djiba B, Niasse M, Diack N, Ndao AC, et al. (2016) Maladies systémiques en médecine interne « contexte africain » aspects épidémiologiques et classification. Rev Med Interne 37(Suppl1): p. 37.

2. Paulsen JI, Rudert H (2001) Manifestations of primary vasculitis in the ENT region. Z Rheumatol 60(4): 219-225.

3. Harari S, Paciocco G, Aramu S (2000) Ear and nose involvement in systemic diseases. Monaldi Arch Chest Dis 55(6): 466-470.

4. Pouchot J, Moya Plana A, Bonfils P (2013) Manifestations ORL et maladies systémiques. Rev Rhum 80(1): 15-19.

5. McCaffrey TV (2009) Nasal manifestations of systemic diseases. Otolaryngol Pol 63(3): 228-235.

6. Alobid I, Guilemany JM, Mullol J (2004) Nasal manifestations of systemic illnesses. Curr Allergy Asthma Rep 4(3): 208-216.

7. Dufour X (2011) Pharyngolaryngeal diseases and medicine. Rev Med Interne 32(Suppl1): 9-11.

8. Beltrán Rodríguez Cabo OE, Tona Acedo G (2011) Role of the ears, nose and throat specialist in the diagnosis and follow up of patients with primary vasculitidies. Reumatol Clin 7(Suppl 3): 7-11.

9. Gera C, Kumar N (2015) Otolaryngologic Manifestations of Various Rheumatic Diseases: Awareness and Practice Among Otolaryngologists. Indian J Otolaryngol Head Neck Surg 67(4): 366-369.

10. Malard, Hamidou M, Toquet C, Bailleuil S, Bordure P, et al. (2002) Relapsing polychondritis revealed by ENT symptoms: clinical characteristics in three patients. Ann Otolaryngol Chir Cervicofac 119(4): 202-208.

11. Rogister F, Kaye 0, Tebache M, Daele J (2015) When rhinosinusitis reveals a systemic disease. Rev Med Liege 70(2): 78-85.

12. Iguelouane N, Skandour D, Rochdi Y, Aderdour L, Raji A (2014) ENT manifestations in systemic diseases about a series of 200 cases. Eur Ann Otorhinolaryngol Head Neck Dis 131(Suppl4) : 127.

13. Parra García GD, Callejas Rubio JL, Ríos Fernández R, Sainz Quevedo M, Ortego Centeno N (2012) Otolaryngologic manifestations of systemic vasculitis. Acta Otorhinolaryngol Esp 63(4): 303-310.

14. Pagnoux C, Teixeira L (2007) Wegener's granulomatosis. Presse Med 36(5 Pt 2): 860-874.

15. Jennette JC, Falk RJ (1997) Small-Vessel vasculitis. N Engl J Med 337(21): $1512-1523$

16. Fauci AS, Haynes BF, Katz P, Wolff SM (1983) Wegener's granulomatosis : prospective clinical and therapeutic experience with 85 patients for 21 years. Ann Intern Med 98(1): 76-85.

17. Hoffman GS, Kerr GS, Leavitt RY, Hallahan CW, Lebovics RS, et al. (1992) Wegener granulomatosis: an analysis of 158 patients. Ann Intern Med 116(6): 488-498.

18. Ceylan A, Asal K, Çelenk F, Köybaşioğlu A (2013) Parotid gland involvement as a presenting feature of Wegener's granulomatosis. Singapore Med J 54(9) : 196-198.

19. Silvera S, Vignaux O, Legmann P (2007) Imagerie des atteintes ORL et cérébrales de la granulomatose de Wegener. Presse Med 36(5): 913-921.

20. Devaney KO, Travis WD, Hoffman G, Leavitt R, Lebovics R, et al. (1990) Interpretation of head and neck biopsies in Wegener's granulomatosis. A pathologic study of 126 biopsies in 70 patients. Am J Surg Pathol 14(6): 555-564

21. Benson Mitchell R, Tolley N, Croft CB, Roberts D (1994) Wegener's granuloma--presenting as a unilateral parotid swelling. J Laryngol Otol 108(5):431-432.

22. Vignes S, Chaillet M, Cabane J, Piette JC (2002) Nasal septal perforation and systemic disease. Rev Med Interne 23(11): 919-926.

23. Lhote F (2007) Churg-Strauss syndrome. Presse Med 36(5 Pt 2): 875889.

24. Bacciu A, Bacciu S, Mercante G, Ingegnoli F, Grasselli C, et al. (2006) Ear, nose and throat manifestations of Churg-Strauss syndrome. Acta Otolaryngol 126(5): 503-509.

25. Bacciu A, Buzio C, Giordano D, Pasanisi E, Vincenti V, et al. (2008) Nasal polyposis in Churg-Strauss syndrome. Laryngoscope 118(2): 325-329.

26. Nakamaru Y, Takagi D, Oridate N, Homma A, Fukuda S (2012) Otolaryngologic manifestations of antineutrophil cytoplasmic antibodyassociated vasculitis. Otolaryngol Head Neck Surg 146(1): 119-121.

27. Lanham JG, Elkon KB, Pusey CD, Hughes GR (1984) Systemic vasculitis with asthma and eosinophilia: a clinical approach to the Churg-Strauss syndrome. Medicine (Baltimore) 63(2): 65-81.

28. Letko E, Zafirakis P, Baltatzis S, Voudouri A, Livir Rallatos C, et al. (2002) Relapsing polychondritis: a clinical review. Semin Arthritis Rheum 31(6): 384-395

29. Baldini C, Talarico R, Della Rossa A, Bombardieri S (2010) Clinical manifestations and treatment of Churg-Strauss syndrome. Rheum Dis Clin North Am 36(3): 527-543.

30. Cogan DG (1945) Syndrome of non-syphilitic interstitial keratitis and vestibuloauditory symptoms. Arch Ophthalmol 33(2): 144-149.

31. Grasland A, Pouchot J, Hachulla E, Blétry O, Papo T, Vinceneux P, et al. (2004) Typical and atypical Cogan's syndrome: 32 cases and review of the literature. Rheumatology (Oxford) 43(8): 1007-1015.

32. Gluth MB, Baratz KH, Matteson EL, Driscoll CL (2006) Cogan syndrome: a retrospective review of 60 patients throughout a half century. Mayo Clin Proc 81(4): 483-488.

33. Vollertsen RS, McDonald TJ, Younge BR, Banks PM, Stanson AW, et al. (1986) Cogan's syndrome: 18 cases and a review of the literature. Mayo Clin Proc 61(5): 344-361.

34. Nandu A, Salu P, Caspers L, Gordts F, Sennesael J (2004) Atypical Cogan's syndrome. Based on a case. Bull Soc Belge Ophtalmol (294): 61-66.

35. Balayre s, Gicquel J, Merci M, Dighiero P (2003) Syndrome de Cogan atypique. J Fr Ophtalmol 26: 64-68.

36. Harris JP, Heydt J, Keithley EM, Chen MC (1997) Immunopathology of the inner ear: an update. Ann N Y Acad Sci 830: 166-178.

37. Holl Ulrich K (2014) Vasculitis: New nomenclature of the Chapel Hill consensus conference 2012. Z Rheumatol 73(9): 823-833.

38. Susac JO, Hardman JM, Selhorst JB (1979) Microangiopathy of the brain and retina. Neurology 29(3): 313-316. 
39. Zenone T (2013) Cogan syndrome. Presse Med 42(6 Pt 1): 951-960.

40. Haynes BF (1981) Successful treatment of sudden hearing loss in Cogan's syndrome with corticosteroids. Arth Rheum 24(3): 501-503.

41. Aubart Cohen F, Klein I, Alexandra JF, Bodaghi B, Doan S, Fardeau C, et al. (2007) Long-term outcome in Susac syndrome. Medicine (Baltimore) 86(2): 93-102.

42. Papo T, Klein I, Sacré K, Doan S, Bodaghi B, et al. (2012) Susac syndrome. Rev Med Interne 33(2): 94-98.

43. Roeser MM, Driscoll CL, Shallop JK, Gifford RH, Kasperbauer JL, et al. (2009) Susac syndrome-a report of cochlear implantation and review of otologic manifestations in twenty-three patients. Otol Neurotol 30(1): 34-40.

44. Ballard E, Butzer JF, Donders J (1996) Susac's syndrome: neuropsychological characteristics in a young man. Neurology 47: 266268.

45. McAdam LP, O’ Hanlan MA, Bluestone R, Pearson CM (1976) Relapsing polychondritis: prospective study of 23 patients and a review of the literature. Medicine (Baltimore) 55(3): 193-215.

46. Papadimitraki ED, Kyrmizakis DE, Kritikos I, Boumpas DT (2004) Earnose-throat manifestations of autoimmune rheumatic diseases. Clin Exp Rheumatol 22(4): 485-494.

47. Roux C, Guey S, Crassard I, Hautefort C, Lioté F, Jouvent E (2011) A rare cause of gait ataxia. Lancet 378(9798): 1274.

48. Kent PD, Michet CJ, Luthra HS (2004) Relapsing polychondritis. Curr Opin Rheumatol 16: 56-61.

49. Casselman JW, Lemahieu SF, Peene P, Stoffels G (1988) Polychondritis affecting the laryngeal cartilages: CT findings. AJR Am J Roentgenol 150(2): 355-356.

50. Eng J, Sabanathan S (1991) Airway complications in relapsing polychondritis. AnnThorac Surg 51: 686-692.

51. Adinolfi A, Valentini E, Calabresi E, Tesei G, Signorini V, et al. (2016) One year in review 2016: systemic lupus erythematosus. Clin Exp Rheumatol 34(4): 569-574.

52. Melikoglu MA, Melikoglu M (2008) The clinical importance of lymphadenopathy in systemic lupus erythematosus. Acta Reumatol Port 33(4): 402-406.

53. Rahman P, Gladman DD, Urowitz MB (1999) Nasal-septal perforation in systemic lupus erythematosus. Time for a closer look. J Rheumatol 26: 1854-1855.

54. Bouomrani S, Nouma H, Chebbi S, Béji M (2015) Atteinte laryngée révélatrice d'un lupus érythémateux systémique. Pan Afr Med J 21: 181.

55. Iacovou E, Vlastarakos PV, Nikolopoulos TP (2014) Laryngeal Involvement in Connective Tissue Disorders. Is it Important for Patient Management? Indian J Otolaryngol Head Neck Surg 66(Suppl 1): 22-29.

56. Tucci M, Quatraro C, Silvestris F (2005) Sjögren's syndrome: an autoimmune disorder with otolaryngological involvement. Acta Otorhinolaryngol Ital 25(3): 139-144.

57. Freeman SR, Sheehan PZ, Thorpe MA, Rutka JA (2005) Ear, nose, and throat manifestations of Sjögren's syndrome: retrospective review of a multidisciplinary clinic. J Otolaryngol 34(1): 20-24.
58. Allen RKA, Sellars RE, Sandstrom PA (2003) A prospective study of 32 patients with neurosarcoidosis. Sarcoidosis Vasc Diffuse Lung Dis 20: 118-125.

59. Tyndel FJ, Davidson GS, Birman H, Modzelewski ZA, Acker JJ (1994) Sarcoidosis of the middle ear. Chest 105: 1582-1583.

60. Verse T, Pirsig W, Heymer B (1997) A case of sarcoidosis of the mastoid. Laryngorhinootologie 76(5): 312-314.

61. Diamantopoulos II, Jones NS (2001) The investigation of nasal septal perforations and ulcers. J Laryngol Otol 115(7): 541-544.

62. Shah UK, White JA, Gooey JE, Hybels RL (1997) Otolaryngologic manifestations of sarcoidosis: presentation and diagnosis. Laryngoscope 107(1): 67-75.

63. Cama E, Santarelli R, Muzzi E, Inches I, Curtolo S, et al. (2011) Sudden hearing loss in sarcoidosis: otoneurological study and neuroradiological correlates. Acta Otorhinolaryngology Ital 31(4): 235-238.

64. Lang EE, el Zaruk J, Colreavy MP, Kennedy S, Rowley H, et al. (2003) An unusual case of external ear inflammation caused by sarcoidosis. Ear Nose Throat J 82(12): 942-945.

65. Schwartzbauer HR, Tami TA (2003) Ear, nose and throat manifestations of sarcoidosis. Otolaryngology Clin N Am 36(4): 673-684.

66. Imran TF, Helfgott S (2015) Respiratory and otolaryngologic manifestations of giant cell arteritis. Clin Exp Rheumatic 33(2 Suppl 89): S-164-170.

67. Maruyoshi H, Toyama K, Kojima S, Kawano H, Ogata N, et al. (2005) Sensorial hearing loss combined with Takayushu's arteritis. Internal Med 44(2): 124-128.

68. Flores Suárez LF, Alba MA1, Tona G (2017) Severe microscopic polyangiitis with unilateral vocal cord paralysis as initial manifestation. Colomb Med (Cali) 48(1): 32-34.

69. Webb CJ, Moots RJ, Swift AC (2008) Ear, nose and throat manifestations of Behçet's disease: a review. J Laryngol Otol 122(12): 1279-1283.

70. Choung YH, Cho MJ, Park K, Choi SJ, Shin YR, et al. (2006) Audio vestibular disturbance in patients with Behçet disease. The laryngoscope 116: 1987-1990.

71. Morales Angulo C, Vergara Pastrana S, Obeso Agüera S, Acle L, González Gay MÁ (2014) Otorhinolaryngological manifestations in patients with Behçet disease. Acta Otorrinolaringol Esp 65(1): 15-21.

72. McCabe BF (1979) Autoimmune sensorineural hearing loss. Ann Otol Rhinol Laryngol 88(5 Pt 1): 585-589.

73. Hervier B, Bordure P, Masseau A, Calais C, Agard C, et al. (2010) Autoimmune sensorineural deafness: physiopathology and therapeutic approach. Rev Med Interne 31(3): 222-228.

74. Marsili M, Marzetti V, Lucantoni M, Lapergola G, Gattorno M, et al. (2016) Autoimmune sensorineural hearing loss as presenting manifestation of paediatric Behçet disease responding to adalimumab: a case report. Ital J Pediatr 42(1): 81. 
(C) (i) This work is licensed under Creative

To Submit Your Article Click Here: Submit Article

DOI: $10.32474 /$ SJ0.2018.01.000113

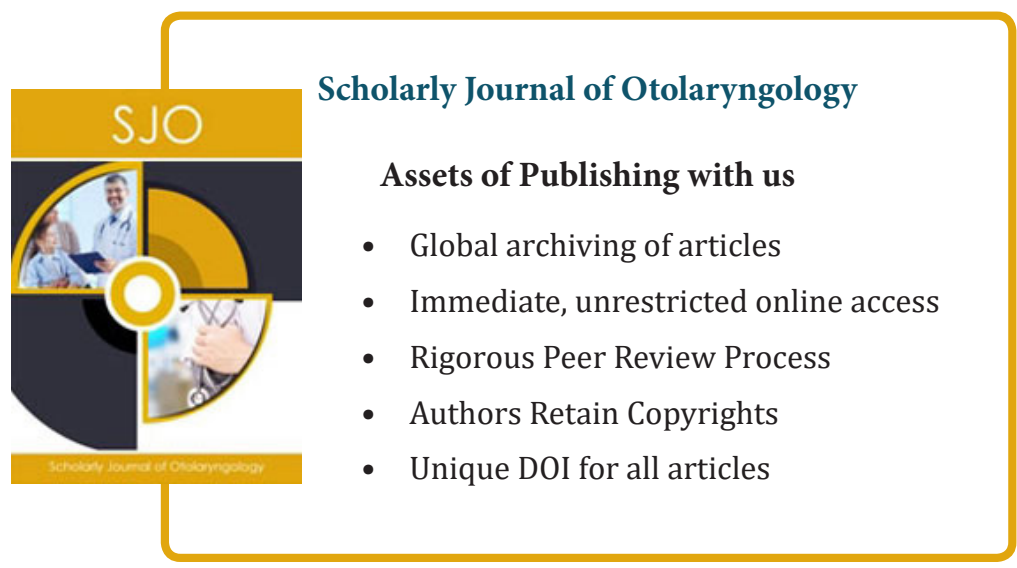

